\title{
UTILIZAÇÃO DE SUBSTRATO COMPOSTO POR RESÍDUOS DA AGROINDÚSTRIA CANAVIEIRA PARA PRODUÇÃO DE MUDAS DE MARACUJAZEIRO-AMARELO ${ }^{1}$
}

\author{
LUIZ AUGUSTO LOPES SERRANO ${ }^{2,3}$, CARLOS MAGNO MAGALHÃES DA SILVA ${ }^{3}$, JUARES OGLIARI ${ }^{3}$, ALMY \\ JUNIOR CORDEIRO DE CARVALHO ${ }^{4}$, CLÁUDIA SALES MARINHO ${ }^{4}$, EDENIO DETMANN ${ }^{5}$
}

\begin{abstract}
RESUMO - Um substrato composto por resíduos da agroindústria canavieira vem sendo utilizado com êxito para a produção de mudas de algumas espécies frutíferas e florestais. Assim, o objetivo deste trabalho foi avaliar o uso deste substrato comparando-o com outros recomendados para a produção de mudas de maracujazeiro-amarelo. Foram avaliados sete substratos: 1- Bagaço de cana + torta de filtro (3:2; v:v); 2- Bagaço de cana + torta de filtro (3:2; v:v) + pulverização foliar semanal com NPK; 3- Bagaço de cana + torta de filttro (3:2; v:v) + 7,3 kg $\mathrm{m}^{-3}$ de Osmocote ${ }^{\circledR}$ (14-14-14); 4- Plantmax ${ }^{\circledR} ; 5$ - Plantmax ${ }^{\circledR}+$ pulverização foliar semanal com NPK; 6- Plantmax $^{\circledR}+7,3 \mathrm{~kg} \mathrm{~m}^{-3}$ Osmocote $^{\circledR}(14-14-$ 14), e 7- Areia + esterco bovino + vermiculita (1:1:1; v:v:v) + NPK. De modo geral, as mudas cultivadas no substrato composto por resíduos da agroindústria canavieira e no substrato comercial, ambos fertilizados com adubo de liberação lenta, foram as que apresentaram melhor estado nutricional, comprovado pelos teores de nutrientes associados ao ótimo crescimento. Portanto, o substrato composto pela mistura bagaço de cana e torta de filtro (3:2; v:v) fertilizado com 7,3 $\mathrm{kg} \mathrm{m}^{-3}$ de Osmocote ${ }^{\circledR}$ (14-14-14) pode ser utilizado para a produção de mudas de maracujazeiro-amarelo.
\end{abstract}

Termos para indexação: Passiflora edulis f. flavicarpa, propagação, adubo de liberação lenta.

\section{USE OF SUBSTRATE CONSISTING OF INDUSTRIAL SUGARCANE PLANT RESIDUES FOR PRODUCTION OF YELLOW PASSION FRUIT SEEDLINGS}

\begin{abstract}
A substrate consisting of industrial sugarcane plant residues has been used with success to the production of some fruitful and forest species seedlings. Then, the objective of this research was to evaluate the use of that substrate, comparing it with other substrates recommended to the production of yellow passion fruit seedlings. It was evaluated seven substrates: 1- Sugarcane bagasse + industrial sugarcane plant residues $(3: 2 ; \mathrm{v}: \mathrm{v})$; 2- Sugarcane bagasse + industrial sugarcane plant residues (3:2; v:v) + NPK foliate spray weekly; 3Sugarcane bagasse + industrial sugarcane plant residues $(3: 2 ; \mathrm{v}: \mathrm{v})+7.3 \mathrm{~kg} \mathrm{~m}^{-3}$ of Osmocote $^{\circledR}(14-14-14) ; 4-$ Plantmax $^{\circledR} ; 5-\mathrm{Plantmax}^{\circledR}+\mathrm{NPK}$ foliate spray weekly; 6- Plantmax ${ }^{\circledR}+7.3 \mathrm{~kg} \mathrm{~m}^{-3}$ Osmocote $^{\circledR}(14-14-14)$ and 7 - Sand + manure + vermiculite $(1: 1: 1$; v:v:v) + NPK. In general, the seedlings cultivated in the substrate consisting of industrial sugarcane plant residues and in the Plantmax ${ }^{\circledR}$, both fertilized with Osmocote ${ }^{\circledR}$, were the ones that presented better nutritional status checked by the appropriate nutrients levels associated to a great growth. Therefore, the substrate composed by the mixture sugarcane bagasse + industrial sugarcane plant residues $\left(3: 2\right.$; v:v) fertilized with $7.3 \mathrm{~kg} \mathrm{~m}^{-3}$ of Osmocote ${ }^{\circledR}$ (14-14-14) can be used for the production of yellow passion fruit seedlings.
\end{abstract}

Index terms: Passiflora edulis f. flavicarpa, propagation, controlled-release fertilizer.

\section{INTRODUÇÃO}

O pomar de maracujazeiro, dependendo dos tratos culturais que recebe, pode ser explorado economicamente por mais de três anos, sendo que a qualidade das mudas - correspondente acerca de $8 \%$ do custo de implantação de um hectare da cultura - torna-se um fator de suma importância para o sucesso da produção. O maracujazeiro pode ser propagado por via sexuada ou assexuada; entretanto, quase que a totalidade dos pomares comerciais são estabelecidos por mudas obtidas de sementes, devido, principalmente, à maior rapidez e facilidade na obtenção das mudas (Lima, 2002).

Atualmente, mudas de diversas fruteiras vêm sendo produzidas em vasos, tubetes ou sacos plásticos, em sistemas protegidos e com o uso de substratos adequados a esse tipo de produção. O cultivo de plantas em substratos permite o controle mais rígido da nutrição mineral e da irrigação de forma a proporcionar melhores condições de crescimento para as plantas. Neste tipo de cultivo, também é possível contornar condições desfavoráveis, comumente enfrentadas com o cultivo tradicional em solo, como a baixa fertilidade química, impedimentos físicos, além de problemas de salinização, incidência de pragas e doenças, contaminações adversas, entre outros (Grassi Filho \& Santos, 2004).
Na seleção de materiais para uso como componentes ou misturas de substratos, busca-se a obtenção de algumas propriedades, como a relação entre as características de aeração e drenagem, o que permitirá o equilíbrio entre a retenção e a liberação da água e dos nutrientes; a adequação nos valores de pH e salinidade, para otimizar a absorção de água e nutrientes pela raiz; a baixa densidade, importante para diminuir os custos de transporte; a ausência de propágulos de doenças, pragas e plantas daninhas, para evitar o uso de defensivos agrícolas, e a homogeneidade, disponibilidade e manutenção da qualidade do material (Kämpf, 2004).

Diversos compostos podem ser utilizados como substratos para o cultivo de espécies vegetais, porém, em algumas situações, pode ser interessante realizar misturas destes para que se possa atingir as melhores condições químicas e físicas para o crescimento das plantas (Grassi Filho \& Santos, 2004).

Para a produção de mudas de maracujazeiro-amarelo, resultados satisfatórios foram obtidos com a utilização de mistura de areia, vermiculita e esterco bovino (1:1:1; v:v:v) fertilizados com NPK e calcário incorporado ao substrato (Oliveira et al., 1993) ou pulverizado semanalmente com NPK (Pereira et al., 2000); esterco bovino puro e misturado com carvão vegetal (São José et al., 1993); substrato comercial à base de vermiculita e casca de pínus moída $\left(\right.$ Plantmax $^{\circledR}$ ) puro (Oliveira et al., 1993) ou fertilizado com 7,3 $\mathrm{kg} \mathrm{m}^{-3}$

\footnotetext{
${ }^{1}$ (Trabalho 45/2005). Recebido: 28-03-2005. Aceito para publicação: 27-07-2006.

${ }^{2}$ Eng. ${ }^{\circ}$ Agr ${ }^{\circ}, M . S c$., Pesquisador Instituto Capixaba de Pesquisa, Assistência Técnica e Extensão Rural - INCAPER, Centro Regional de Desenvolvimento Rural Nordeste, Rodovia BR 101 norte, Km 151, Caixa Postal 62, 29900-970, Linhares-ES, lalserrano@incaper.es.gov.br;

${ }^{3}$ Eng. $^{\circ}$ Agr ${ }^{\circ}, M . S c$., Doutorando em Produção Vegetal, Bolsista CNPq, Universidade Estadual do Norte Fluminense 'Darcy Ribeiro' - UENF/CCTA/LFIT, Av. Alberto Lamego 2000, Horto, 28015-620, Campos dos Goytacazes-RJ;

${ }^{4}$ Eng. $^{\circ}$ Agr $^{\circ}$, D.Sc., Professor, Universidade Estadual do Norte Fluminense 'Darcy Ribeiro' - UENF/CCTA/LFIT;

${ }^{5}$ Zootecnista, D.Sc., Professor, Universidade Federal de Viçosa - UFV/DZO/LNA, Av. P.H. Rolfs, 36571-000, Viçosa-MG.

Apoio Financeiro: CNPq, FAPERJ, Usina Barcelos S/A.
} 
de Osmocote ${ }^{\circledR}$, fórmula NPK 14-14-14 (Silva et al., 2001).

No norte do Estado do Rio de Janeiro, o uso do substrato composto por resíduos da agroindústria canavieira, advindo da mistura bagaço de cana moído e torta de filtro, tem sido utilizado com êxito para produção de mudas de cana-de-açúcar e eucalipto (Morgado, 1998), goiabeira (Schiavo \& Martins, 2002) e citros (Serrano et al., 2004). Os resultados demonstram que este substrato é adequado para essa finalidade, pois conferiu às mudas qualidades morfofisiológicas semelhantes ou superiores às alcançadas com o uso de substratos comerciais.

Este trabalho teve por objetivo avaliar a viabilidade do uso do substrato composto por resíduos da agroindústria de cana-deaçúcar para a produção de mudas de maracujazeiro-amarelo (Passiflora edulis Sims f. flavicarpa DEG).

\section{MATERIAL E MÉTODOS}

O trabalho foi realizado em casa de vegetação na UENF, em Campos dos Goytacazes-RJ, entre setembro e dezembro de 2003, com temperatura média do período de $23,4^{\circ} \mathrm{C}$, sendo $30,0^{\circ} \mathrm{C}$ a média das máximas e $19,6^{\circ} \mathrm{C}$ a média das mínimas.

$\mathrm{O}$ experimento foi instalado sob delineamento em blocos casualizados completos, com sete tratamentos e cinco blocos que continham duas repetições (parcelas) de cada tratamento. Cada parcela experimental era composta por 24 plantas, das quais seis constituíram a parcela útil, totalizando 12 repetições por tratamento por bloco.

Foram utilizados sete substratos (tratamentos): 1- Bagaço de cana + torta de filtro $(3: 2 ; \mathrm{v}: \mathrm{v}) ; \mathbf{2}$ - Bagaço de cana + torta de filtro $(3: 2 ; \mathrm{v}: \mathrm{v})+$ pulverização foliar semanal com NPK; 3- Bagaço de cana + torta de filtro $(3: 2 ; \mathrm{v}: \mathrm{v})+7,3 \mathrm{~kg} \mathrm{~m}^{-3}$ de Osmocote ${ }^{\circledR}(14-14-14) ; 4$

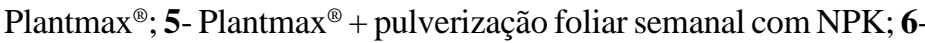
Plantmax $^{\circledR}+7,3 \mathrm{~kg} \mathrm{~m}^{-3}$ Osmocote $^{\circledR}$ (14-14-14), e 7- Areia + esterco bovino + vermiculita $(1: 1: 1 ; \mathrm{v}: \mathrm{v}: \mathrm{v})+10 \mathrm{~kg} \mathrm{~m}^{-3}$ de superfosfato simples, $6 \mathrm{~kg} \mathrm{~m}^{-3}$ de cloreto de potássio, $2 \mathrm{~kg} \mathrm{~m}^{-3}$ de uréia e $8 \mathrm{~kg} \mathrm{~m}^{-3}$ de calcário dolomítico.

As características químicas dos substratos utilizados no experimento são apresentadas na Tabela 1, sendo que as mesmas foram realizadas pelo Laboratório de Análises de Solos da UFRRJ.

A solução utilizada nas pulverizações foliares foi estabelecida segundo critérios de Pereira et al. (2000), sendo a mesma composta por $1 \mathrm{~g} \mathrm{~L}^{-1}$ de sulfato de amônio, $1 \mathrm{~g} \mathrm{~L}^{-1}$ de superfosfato simples e 0,5 $\mathrm{g} \mathrm{L}^{-1}$ de cloreto de potássio, enquanto a adubação do substrato 7 foi baseada em recomendação de Oliveira et al. (1993).

O substrato composto pela mistura bagaço de cana e torta de filtro (3:2; v:v) foi submetido a compostagem em julho de 2003, sendo que o mesmo foi disposto em montes de $1 \mathrm{~m}$ de altura por $3 \mathrm{~m}$ de largura, cobertos por lona de polipropileno preta. Foram realizados irrigações e revolvimento dos montes duas vezes por semana. Ao final de 70 dias, o composto estava apto ao uso, apresentando condutividade elétrica de $4,0 \mathrm{dS} \mathrm{m}^{-1}$, densidade aparente de $190 \mathrm{~g} \mathrm{~L}^{-}$ ${ }^{1}$ e porosidade total de $90 \%$ (macroporosidade de $75 \%$ e microporosidade de $15 \%$ ).

As sementes utilizadas foram extraídas de frutos ovais bem desenvolvidos de pomares comerciais vigorosos e produtivos da região, sendo utilizadas três sementes por recipiente (sacos plásticos de $15 \times 27 \mathrm{~cm}$ ), com posterior desbaste após as plântulas terem atingido $5 \mathrm{~cm}$ de altura, deixando apenas uma plântula por recipiente.

Foram avaliados a altura das plantas, o número de folhas e o diâmetro do caule aos 30; 40; 50 e 60 dias após a semeadura, com o objetivo de quantificar o diferencial de crescimento entre as épocas, sendo que, após a última avaliação, foi extraída a parte aérea, com corte rente ao colo, e as raízes foram separadas dos substratos utilizando-se de água corrente, com posterior medição do comprimento da raiz principal. As folhas foram retiradas para avaliação da área foliar em aparelho LI-3100 area meter ${ }^{\circledR}$ e juntamente com caules e raízes foram colocados para secar em estufa de circulação forçada de ar $\left(70^{\circ} \mathrm{C}\right.$ por 72 horas $)$ para posterior determinação, por gravimetria, da massa seca do sistema radicular e da massa seca da parte aérea.

Posteriormente, as folhas secas (com pecíolo) foram trituradas em moinho tipo Willey para realização da quantificação dos teores foliares de N, P, K, Ca, Mg, S, B, Cu, Fe, Mn e Zn.

No planejamento do trabalho, optou-se, para comparação das médias, pela utilização de testes diferenciados para cada variável estudada (crescimento, diferencial de crescimento e teor nutricional), baseando-se nos coeficientes de variação das mesmas, obtidos em trabalhos semelhantes, visando a aumentar a confiabilidade das informações obtidas após análise estatística (Cardellino \& Siewerdt, 1992). Os dados foram submetidos à análise de variância, e as médias de crescimento foram comparadas pelo teste SNK, as de teores foliares, pelo teste de Tukey, e as dos diferenciais de crescimento foram comparadas pelo teste de Scheffé, todos a 5\%, sendo utilizado o programa Statistical Analysis System (SAS, 1998).

\section{RESULTADOS E DISCUSSÃO}

Aos 60 dias após a semeadura (DAS), as mudas produzidas nos tratamentos 3 e 6 apresentaram maiores médias de altura, área foliar e massa seca da parte aérea (Tabela 2), resultado semelhante aos obtidos por São José et al. (1993), ao utilizarem esterco bovino puro e misturado com carvão vegetal $(50 \%)$, e por Peixoto et al. (1999), ao utilizarem $400 \mathrm{~L}$ de esterco aviário por $\mathrm{m}^{3}$ de solo; e superior aos obtidos por Peixoto \& Pádua (1989), Borges et al. (1995) e Lima et al. (1995), que utilizaram substratos com várias relações de mistura entre solo e esterco.

Segundo Kozlowski et al. (1991), mudas com maior área foliar na época de serem levadas para o campo apresentam crescimento

TABELA 1 - Composição química dos substratos utilizados para a produção de mudas de maracujazeiro-amarelo. UENF, Campos dos Goytacazes - RJ, 2003.

\begin{tabular}{|c|c|c|c|c|c|c|c|c|c|c|c|c|c|}
\hline \multirow{2}{*}{ Substratos ${ }^{1}$} & \multirow{2}{*}{$\underset{\left(\mathbf{H}_{2} \mathbf{O}\right)}{\mathbf{p H}}$} & $\mathbf{N}$ & $\mathbf{P}_{2} \mathbf{O}_{5}$ & $\mathbf{K}_{2} \mathbf{O}$ & $\mathrm{Ca}$ & Mg & $\mathbf{S}$ & $\mathrm{C}$ & $\mathbf{F e}$ & $\mathrm{Cu}$ & Zn & Mn & B \\
\hline & & \multicolumn{7}{|c|}{$\mathrm{g} \mathrm{kg}^{-1}$} & \multicolumn{5}{|c|}{$\mathrm{mg} \mathrm{kg}^{-1}$} \\
\hline 1 & 7,0 & 17,85 & 20,06 & 2,74 & 17,4 & 4,0 & 1,59 & 266,4 & 18.480 & 60 & 348 & 850 & 16,29 \\
\hline 2 & 7,0 & 17,85 & 20,06 & 2,74 & 17,4 & 4,0 & 1,59 & 266,4 & 18.480 & 60 & 348 & 850 & 16,29 \\
\hline 3 & 6,3 & 20,18 & 24,18 & 8,28 & 18,0 & 3,6 & 1,59 & 199,2 & 16.800 & 56 & 332 & 800 & 12,50 \\
\hline 4 & 4,7 & 8,85 & 11,27 & 6,51 & 14,6 & 21,6 & 3,29 & 314,4 & 17.220 & 28 & 84 & 235 & 18,37 \\
\hline 5 & 4,7 & 8,85 & 11,27 & 6,51 & 14,6 & 21,6 & 3,29 & 314,4 & 17.220 & 28 & 84 & 235 & 18,37 \\
\hline 6 & 5,1 & 12,60 & 11,95 & 10,29 & 16,2 & 24,0 & 2,41 & 295,2 & 18.060 & 32 & 72 & 245 & 15,34 \\
\hline 7 & 7,1 & 5,18 & 8,52 & 15,09 & 11,0 & 16,8 & 1,29 & 50,4 & 10.080 & 20 & 76 & 160 & 8,71 \\
\hline
\end{tabular}

1 1- Bagaço de cana + torta de filtro $(3: 2 ; \mathrm{v}: \mathrm{v}) ; \mathbf{2}$ - Bagaço de cana + torta de filtro $(3: 2 ; \mathrm{v}: \mathrm{v})+$ pulverização foliar semanal com NPK; 3- Bagaço de cana + torta de filtro $(3: 2 ; \mathrm{v}: \mathrm{v})+7,3 \mathrm{~kg} \mathrm{~m}^{-3}$ de Osmocote ${ }^{\circledR}(14-14-14) ; 4$ - Plantmax $^{\circledR} ;$ 5- Plantmax ${ }^{\circledR}+{\text { pulverização foliar semanal com } \text { NPK} \text {; 6- Plantmax }}^{\circledR}+7,3$ kg $\mathrm{m}^{-3}$ Osmocote $^{\circledR}(14-14-14)$ e; 7- Areia + esterco bovino + vermiculita (1:1:1; v:v:v) $+10 \mathrm{~kg} \mathrm{~m}^{-3}$ de superfosfato simples $+6 \mathrm{~kg}^{-3}$ de cloreto de potássio + $2 \mathrm{~kg} \mathrm{~m}^{-3}$ de uréia $+8 \mathrm{~kg} \mathrm{~m}^{-3}$ de calcário dolomítico. 
TABELA 2 - Valores médios da altura (ALT), diâmetro de caule (DC), número de folhas (NF), área foliar (AF), massa seca da parte aérea (MSPA), massa seca do sistema radicular (MSSR) e comprimento de raiz (CR) de mudas de maracujazeiro-amarelo aos 60 dias após a semeadura ${ }^{1}$. UENF, Campos dos Goytacazes - RJ, 2003.

\begin{tabular}{cccccccc}
\hline Substratos $^{2}$ & ALT $(\mathbf{c m})$ & DC $(\mathbf{m m})$ & NF $(\mathbf{l n})$ & AF $\left(\mathbf{c m}^{\mathbf{2}}\right)$ & MSPA $(\mathbf{g})$ & MSSR $(\mathbf{g})$ & CR $(\mathbf{c m})$ \\
\hline $\mathbf{1}$ & $15,68 \mathrm{~d}$ & $1,80 \mathrm{~b}$ & $2,1663 \mathrm{c}$ & $148,88 \mathrm{~d}$ & $0,51 \mathrm{~d}$ & $0,15 \mathrm{c}$ & $17,66 \mathrm{~d}$ \\
$\mathbf{2}$ & $17,65 \mathrm{~d}$ & $2,03 \mathrm{~b}$ & $2,2106 \mathrm{c}$ & $177,20 \mathrm{~d}$ & $0,65 \mathrm{~d}$ & $0,18 \mathrm{c}$ & $16,76 \mathrm{~d}$ \\
$\mathbf{3}$ & $62,84 \mathrm{a}$ & $3,84 \mathrm{a}$ & $2,6151 \mathrm{a}$ & $909,93 \mathrm{a}$ & $5,56 \mathrm{a}$ & $1,18 \mathrm{~b}$ & $36,13 \mathrm{bc}$ \\
$\mathbf{4}$ & $38,64 \mathrm{c}$ & $3,35 \mathrm{a}$ & $2,4677 \mathrm{~b}$ & $500,50 \mathrm{c}$ & $2,91 \mathrm{c}$ & $0,96 \mathrm{~b}$ & $41,06 \mathrm{a}$ \\
$\mathbf{5}$ & $43,51 \mathrm{bc}$ & $3,57 \mathrm{a}$ & $2,4556 \mathrm{~b}$ & $469,51 \mathrm{c}$ & $2,90 \mathrm{c}$ & $0,92 \mathrm{~b}$ & $40,14 \mathrm{ab}$ \\
$\mathbf{6}$ & $56,30 \mathrm{ab}$ & $3,83 \mathrm{a}$ & $2,5819 \mathrm{a}$ & $897,02 \mathrm{a}$ & $4,75 \mathrm{ab}$ & $1,09 \mathrm{~b}$ & $36,81 \mathrm{bc}$ \\
$\mathbf{7}$ & $48,98 \mathrm{bc}$ & $3,51 \mathrm{a}$ & $2,5641 \mathrm{a}$ & $727,17 \mathrm{~b}$ & $3,94 \mathrm{bc}$ & $1,59 \mathrm{a}$ & $33,18 \mathrm{c}$ \\
\hline Média Geral & 40,51 & 3,13 & 2,4373 & 547,17 & 3,03 & 0,87 & 31,68 \\
\hline $\mathbf{C v} \mathbf{( \% )}$ & 28,45 & 15,17 & 5,10 & 34,82 & 41,30 & 52,77 & 18,59 \\
\hline
\end{tabular}

${ }^{1}$ Médias na coluna, seguidas por letras diferentes, são diferentes a $5 \%$ de probabilidade, pelo teste SNK.

2- Bagaço de cana + torta de filtro (3:2; v:v); 2- Bagaço de cana + torta de filtro (3:2; v:v) + pulverização foliar semanal com NPK; 3- Bagaço de cana + torta de filtro (3:2; v:v) + 7,3 $\mathrm{kg} \mathrm{m}^{-3}$ de Osmocote $^{\circledR}(14-14-14) ;$ 4- Plantmax ${ }^{\circledR} ;$ 5- Plantmax ${ }^{\circledR}+$ pulverização foliar semanal com NPK; 6- Plantmax $^{\circledR}+7,3 \mathrm{~kg}$ $\mathrm{m}^{-3}$ Osmocote ${ }^{\circledR}$ (14-14-14) e; 7- Areia + esterco bovino + vermiculita (1:1:1; v:v:v) $+10 \mathrm{~kg} \mathrm{~m}^{-3}$ de superfosfato simples $+6 \mathrm{~kg} \mathrm{~m}^{-3}$ de cloreto de potássio + $2 \mathrm{~kg} \mathrm{~m}^{-3}$ de uréia $+8 \mathrm{~kg} \mathrm{~m}^{-3}$ de calcário dolomítico.

inicial mais rápido, em virtude da maior produção de fotoassimilados e posterior drenagem para outras partes da planta. Já a massa seca da parte aérea é considerada como uma boa indicação da capacidade de resistência das mudas às condições adversas após o plantio no campo (Morgado, 1998).

Enquanto alguns autores recomendam que a muda seja transplantada para o campo quando surge a primeira gavinha (Borges et al., 1995; Lima et al., 1995), outros sugerem o transplante quando estas atingem a altura de $20 \mathrm{~cm}$ (Pereira et al., 2000). As mudas cultivadas nos substratos 3 e 6 foram as que atingiram mais precocemente a altura de $20 \mathrm{~cm}$, sendo que, aos 50 DAS, estas apresentaram maiores médias, 27,4 e $24,9 \mathrm{~cm}$, respectivamente, enquanto Pereira et al. (2000) obtiveram, no geral, mudas aptas ao transplantio aos 66 DAS. A emissão da primeira gavinha, nos tratamentos 3 e 6 , iniciou-se entre os 50 e 60 DAS. Borges et al. (1995) e Lima et al. (1995) observaram a emissão da primeira gavinha aos 79 DAS.

A maior média para massa seca do sistema radicular foi obtida pelas mudas produzidas no tratamento 7 , e as maiores médias para o comprimento da raiz foram obtidas pelas mudas produzidas nos tratamentos 4 e 5 (Tabela 2). Entretanto, as mudas produzidas nos tratamentos 3 e 6 apresentaram bom crescimento do sistema radicular, com massa seca de $1,18 \mathrm{~g}$ e $1,09 \mathrm{~g}$ e comprimento da raiz de $36,1 \mathrm{~cm}$ e $36,8 \mathrm{~cm}$, respectivamente. Peixoto \& Pádua (1989) e Peixoto et al.
(1999) observaram máxima massa seca do sistema radicular de $0,30 \mathrm{~g}$ e 0,69 g e máximo comprimento da raiz principal de $26,2 \mathrm{~cm}$ e $30,8 \mathrm{~cm}$, respectivamente.

As mudas cultivadas nos tratamentos 3; 6 e 7 apresentaramse entre as de maiores médias de incremento de altura em todos os intervalos avaliados, desde os 30 até os 60 DAS (Tabela 3). Em relação ao diâmetro do caule, as mudas cultivadas nos tratamentos 3; 4; 5; 6 e 7 apresentaram maior incremento nos intervalos de 30 a 40 e de 40 a 50 DAS, e no intervalo final, de 50 a 60 DAS, o incremento foi semelhante em todos os tratamentos. Para o número de folhas, o incremento nas mudas foi semelhante em todos os tratamentos nos dois primeiros períodos, mas, no último período, as mudas dos substratos 4 e 5 apresentaram os menores incrementos.

Os teores foliares obtidos (Tabela 4), para todos os nutrientes analisados, estão dentro das faixas de obtenção de máxima produtividade de frutos em plantas adultas de maracujazeiro-amarelo (Carvalho et al., 2001), com exceção somente para os teores de N nas mudas cultivadas nos substratos 4 e 5 e para o teor de $\mathrm{S}$ nas cultivadas no substrato 5 , sendo observados, nestes casos, clorose uniforme nas folhas.

Observa-se, na Tabela 1, que os substratos 4; 5 e 7 apresentaram os menores teores de $\mathrm{N}$, porém a adubação realizada no substrato 7 supriu as mudas quanto a este nutriente, enquanto o substrato 4 não recebeu adubação, e a pulverização no substrato 5

TABELA 3 - Diferencial de crescimento entre épocas (dias após semeadura - DAS), para altura, diâmetro do caule e número de folhas em mudas de maracujazeiro-amareloํ. UENF, Campos dos Goytacazes - RJ, 2003.

\begin{tabular}{|c|c|c|c|c|c|c|c|c|c|}
\hline \multirow{2}{*}{$\begin{array}{c}\text { Substratos }^{2} / \\
\text { DAS }\end{array}$} & \multicolumn{3}{|c|}{ Diferencial altura (cm) } & \multicolumn{3}{|c|}{ Diferencial diâmetro (mm) } & \multicolumn{3}{|c|}{ Diferencial $n^{0}$ folhas (ln) } \\
\hline & $30-40$ & $40-50$ & $50-60$ & $30-40$ & $40-50$ & $50-60$ & $30-40$ & $40-50$ & $50-60$ \\
\hline 1 & $0,80 \mathrm{~b}$ & $2,81 \mathrm{~b}$ & $8,27 \mathrm{c}$ & $0,10 \mathrm{~b}$ & $0,24 \mathrm{bc}$ & $0,49 \mathrm{a}$ & $0,3136 \mathrm{a}$ & $0,4121 \mathrm{a}$ & $0,2460 \mathrm{a}$ \\
\hline 2 & $1,08 \mathrm{~b}$ & $3,05 \mathrm{~b}$ & $9,92 \mathrm{c}$ & $0,18 \mathrm{~b}$ & $0,16 \mathrm{c}$ & $0,69 \mathrm{a}$ & $0,3811 \mathrm{a}$ & $0,4098 \mathrm{a}$ & $0,1907 \mathrm{ab}$ \\
\hline 3 & $6,60 \mathrm{a}$ & $13,92 \mathrm{a}$ & $35,41 \mathrm{a}$ & $0,94 \mathrm{a}$ & $0,58 \mathrm{ab}$ & $0,60 \mathrm{a}$ & $0,3315 \mathrm{a}$ & $0,3845 \mathrm{a}$ & $0,1864 \mathrm{ab}$ \\
\hline 4 & $5,28 \mathrm{a}$ & $10,04 \mathrm{a}$ & $17,63 \mathrm{bc}$ & $0,85 \mathrm{a}$ & $0,43 \mathrm{abc}$ & $0,60 \mathrm{a}$ & $0,2952 \mathrm{a}$ & $0,3431 \mathrm{a}$ & $0,1227 \mathrm{~b}$ \\
\hline 5 & $6,43 \mathrm{a}$ & $12,34 \mathrm{a}$ & $18,74 \mathrm{bc}$ & $0,76 \mathrm{a}$ & $0,63 \mathrm{a}$ & $0,57 \mathrm{a}$ & $0,3057 \mathrm{a}$ & $0,3074 \mathrm{a}$ & $0,0942 \mathrm{~b}$ \\
\hline 6 & $5,81 \mathrm{a}$ & $13,31 \mathrm{a}$ & $31,31 \mathrm{ab}$ & $0,93 \mathrm{a}$ & $0,62 \mathrm{a}$ & $0,80 \mathrm{a}$ & $0,2981 \mathrm{a}$ & $0,3682 \mathrm{a}$ & $0,1967 \mathrm{ab}$ \\
\hline 7 & $5,15 \mathrm{a}$ & $10,75 \mathrm{a}$ & $27,58 \mathrm{ab}$ & $0,73 \mathrm{a}$ & $0,51 \mathrm{abc}$ & $0,76 \mathrm{a}$ & $0,3425 \mathrm{a}$ & $0,3845 \mathrm{a}$ & $0,1607 \mathrm{ab}$ \\
\hline dms & 1,59 & 5,84 & 14,34 & 0,21 & 0,37 & 0,42 & 0,1306 & 0,1148 & 0,1137 \\
\hline
\end{tabular}

${ }^{1}$ Médias na coluna, seguidas por letras diferentes, são diferentes a 5\% de probabilidade, pelo teste de Scheffé.

2 1- Bagaço de cana + torta de filtro $(3: 2 ; \mathrm{v}: \mathrm{v}) ; \mathbf{2}$ - Bagaço de cana + torta de filtro $(3: 2 ; \mathrm{v}: \mathrm{v})+$ pulverização foliar semanal com NPK; 3 - Bagaço

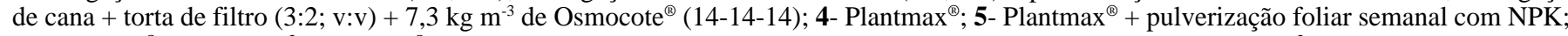

6- Plantmax ${ }^{\circledR}+7,3 \mathrm{~kg} \mathrm{~m}^{-3}$ Osmocote $^{\circledR}(14-14-14)$ e; 7- Areia + esterco bovino + vermiculita $(1: 1: 1 ; \mathrm{v}: \mathrm{v}: \mathrm{v})+10 \mathrm{~kg}^{-3} \mathrm{de} \mathrm{superfosfato} \mathrm{simples}^{-1}$

$+6 \mathrm{~kg} \mathrm{~m}^{-3}$ de cloreto de potássio $+2 \mathrm{~kg} \mathrm{~m}^{-3}$ de uréia $+8 \mathrm{~kg} \mathrm{~m}^{-3}$ de calcário dolomítico. 
TABELA 4 - Teores foliares médios de macronutrientes e micronutrientes de mudas de maracujazeiro-amarelo aos 60 dias após a semeadura ${ }^{1}$. UENF, Campos dos Goytacazes - RJ, 2003.

\begin{tabular}{|c|c|c|c|c|c|c|c|c|c|c|c|}
\hline \multirow{2}{*}{ Substratos $^{2}$} & $\mathbf{N}$ & $\mathbf{P}$ & $\mathbf{K}$ & $\mathbf{C a}$ & Mg & $\mathbf{S}$ & $\mathbf{F e}$ & Mn & $\mathbf{C u}$ & Zn & B \\
\hline & \multicolumn{6}{|c|}{$\mathrm{g} \mathrm{kg}^{-1}$} & \multicolumn{5}{|c|}{$\mathrm{mg} \mathrm{kg}^{-1}$} \\
\hline 1 & $41,25 \mathrm{a}$ & $5,98 \mathrm{a}$ & $34,80 \mathrm{a}$ & $19,28 \mathrm{~b}$ & $4,34 \mathrm{a}$ & $3,55 \mathrm{ab}$ & $117,67 \mathrm{c}$ & $65,12 \mathrm{c}$ & $15,19 \mathrm{~d}$ & $39,36 \mathrm{~b}$ & $55,77 \mathrm{a}$ \\
\hline 2 & $42,15 \mathrm{a}$ & $5,86 \mathrm{a}$ & $37,40 \mathrm{a}$ & $19,17 \mathrm{~b}$ & $4,06 \mathrm{ab}$ & $3,56 a b$ & $115,65 \mathrm{c}$ & $55,79 \mathrm{c}$ & $14,93 \mathrm{~d}$ & $34,91 \mathrm{~b}$ & $52,21 \mathrm{a}$ \\
\hline 3 & $47,58 \mathrm{a}$ & $5,30 \mathrm{a}$ & $38,70 \mathrm{a}$ & $25,53 \mathrm{a}$ & $3,26 \mathrm{c}$ & $3,76 a b$ & $124,18 \mathrm{bc}$ & $124,40 \mathrm{~b}$ & $44,95 \mathrm{bcd}$ & $61,12 \mathrm{a}$ & $38,12 \mathrm{~b}$ \\
\hline 4 & $22,65 \mathrm{~b}$ & $3,27 \mathrm{c}$ & $37,00 \mathrm{a}$ & $24,17 \mathrm{a}$ & $3,31 \mathrm{bc}$ & $3,16 \mathrm{bc}$ & $171,26 \mathrm{a}$ & 195,92 a & $78,41 \mathrm{a}$ & $37,76 \mathrm{~b}$ & $51,58 \mathrm{a}$ \\
\hline 5 & $20,50 \mathrm{~b}$ & $3,12 \mathrm{c}$ & $37,90 \mathrm{a}$ & $25,33 \mathrm{a}$ & $2,97 \mathrm{c}$ & $2,67 \mathrm{c}$ & $168,50 \mathrm{a}$ & $197,35 \mathrm{a}$ & $73,58 \mathrm{ab}$ & $35,82 \mathrm{~b}$ & $52,25 \mathrm{a}$ \\
\hline 6 & $43,70 \mathrm{a}$ & $4,89 \mathrm{ab}$ & $40,10 \mathrm{a}$ & $19,55 \mathrm{~b}$ & $3,04 \mathrm{c}$ & $4,29 \mathrm{a}$ & $163,88 a b$ & 194,73 a & $47,41 \mathrm{bc}$ & $40,58 \mathrm{~b}$ & $44,96 \mathrm{ab}$ \\
\hline 7 & $36,47 \mathrm{a}$ & $4,13 \mathrm{bc}$ & $38,05 \mathrm{a}$ & $19,99 \mathrm{~b}$ & $4,79 \mathrm{a}$ & $3,62 \mathrm{ab}$ & $116,42 \mathrm{c}$ & $63,26 \mathrm{c}$ & $40,01 \mathrm{~cd}$ & $23,49 \mathrm{c}$ & $46,17 \mathrm{ab}$ \\
\hline Média Geral & 36,39 & 4,65 & 37,70 & 21,86 & 3,68 & 3,51 & 139,65 & 128,08 & 44,93 & 39,00 & 48,72 \\
\hline dms & 11,11 & 1,15 & 7,33 & 3,53 & 0,80 & 0,87 & 43,36 & 41,55 & 30,33 & 10,43 & 10,82 \\
\hline CV (\%) & 15,07 & 12,23 & 9,57 & 7,97 & 10,74 & 12,24 & 15,29 & 15,98 & 33,26 & 13,18 & 10,94 \\
\hline
\end{tabular}

${ }^{1}$ Médias na coluna, seguidas por letras diferentes, são diferentes a 5\% de probabilidade, pelo teste Tukey.

2 1- Bagaço de cana + torta de filtro $(3: 2 ; \mathrm{v}: \mathrm{v}) ; \mathbf{2}$ - Bagaço de cana + torta de filtro $(3: 2 ; \mathrm{v}: \mathrm{v})+$ pulverização foliar semanal com NPK; 3- Bagaço de cana + torta de filtro $(3: 2 ; \mathrm{v}: \mathrm{v})+7,3 \mathrm{~kg} \mathrm{~m}^{-3}$ de Osmocote ${ }^{\circledR}(14-14-14) ;$ 4- Plantmax ${ }^{\circledR}$; 5 - Plantmax ${ }^{\circledR}+{\text { pulverização foliar semanal com } \text { NPK} \text {; 6- Plantmax }}^{\circledR}+7,3 \mathrm{~kg}$ $\mathrm{m}^{-3}$ Osmocote ${ }^{\circledR}(14-14-14)$ e; 7 - Areia + esterco bovino + vermiculita (1:1:1; v:v:v) $+10 \mathrm{~kg} \mathrm{~m}^{-3}$ de superfosfato simples $+6 \mathrm{~kg} \mathrm{~m}^{-3}$ de cloreto de potássio + $2 \mathrm{~kg} \mathrm{~m}^{-3}$ de uréia $+8 \mathrm{~kg} \mathrm{~m}^{-3}$ de calcário dolomítico.

parece não ter surtido efeito. As mudas que apresentaram altos teores de $\mathrm{N}$ na matéria seca foliar foram as cultivadas no substrato 6, que recebeu adubação com fertilizante de liberação lenta (Tabela 4), e no substrato composto por resíduos da agroindústria canavieira, que apresenta alto teor de $\mathrm{N}$ (Tabela 1), porém o crescimento das mudas neste último só foi satisfatório quando se utilizou fertilizante de liberação lenta (Tabela 2).

A maior extração de macronutrientes foi observada para N, K e Ca, confirmando Lima (2002), e com relação aos micronutrientes, os mais extraídos foram $\mathrm{Mn}$ e $\mathrm{Fe}$, entretanto os níveis de $\mathrm{B}, \mathrm{Zn} \mathrm{e} \mathrm{Cu}$ estiveram acima da faixa citada por Carvalho et al. (2001). É importante destacar o alto teor de $\mathrm{P}$ no substrato composto por resíduos da agroindústria canavieira (Tabela 1), o que conferiu alto teor deste macronutriente nas mudas cultivadas neste substrato, mesmo quando não houve adubação (Tabela 4).

As mudas cultivadas nos substratos 3 e 6 foram as que apresentaram melhor estado nutricional comprovado pelos teores de nutrientes associados ao ótimo crescimento, em virtude de o Osmocote ${ }^{\circledR}$ permitir a disponibilidade contínua de nutrientes para as mudas, minimizando, assim, a probabilidade de ocorrer deficiências nutricionais durante o período de formação das mudas em comparação à utilização de fertilizantes solúveis, os quais podem ser lixiviados mais rapidamente.

\section{CONCLUSÕES}

1) O substrato composto pela mistura de bagaço de cana + torta de filtro (3:2; v:v) e o substrato comercial, ambos fertilizados com adubo de liberação lenta, foram os que conferiram maior crescimento e melhor estado nutricional às mudas de maracujazeiroamarelo, comprovado pelos teores de nutrientes associados ao ótimo crescimento.

2) O substrato composto por resíduos da agroindústria canavieira, fertilizado com adubo de liberação lenta, pode ser utilizado para a produção de mudas de maracujazeiro-amarelo.

\section{REFERÊNCIAS}

BORGES, A.L.; LIMA, A.A.; CALDAS, R.C. Adubação orgânica e química na formação de mudas de maracujazeiros. Revista Brasileira de Fruticultura, Cruz das Almas, v.17, n.2, p.17-22, 1995.

CARDELLINO, R.A.; SIEWERDT, F. Utilização correta e incorreta dos testes de comparação de médias. Revista da Sociedade Brasileira de Zootecnia, Viçosa, v.21, n.6, p.985-995, 1992.
CARVALHO, A.J.C.; MARTINS, D.P.; MONNERAT, P.H.; BERNADO, S.; SILVA, J.A. Teores de nutrientes foliares no maracujazeiro amarelo associados à estação fenológica, adubação potássica e lâminas de irrigação. Revista Brasileira de Fruticultura, Jaboticabal, v.23, n.2, p.403-408, 2001.

GRASSI FILHO, H.; SANTOS, C.H. Importância da relação entre os fatores hídricos e fisiológicos no desenvolvimento de plantas cultivadas em substratos. In: BARBOSA, J.G.; MARTINEZ, H.E.P.; PEDROSA, M.W.; SEDIYAMA, M.A.N. (Eds.) Nutrição e adubação de plantas cultivadas em substrato. Viçosa: UFV, 2004.p.78-91.

KÄMPF, A. Evolução e perspectivas do crescimento do uso de substratos no Brasil. In: BARBOSA, J.G.; MARTINEZ, H.E.P.; PEDROSA, M.W.; SEDIYAMA, M.A.N.(Eds.) Nutrição e adubação de plantas cultivadas em substrato. Viçosa: UFV, 2004. p.03-10.

KOZLOWSKI, T.T.; KRAMER, P.J.; PALLARDY, S.G. The physiological ecology of woody plants. New York: Academic Press, 1991.657p.

LIMA, A.A.; BORGES, A.L.; CALDAS, R.C. Substratos para produção de mudas de maracujazeiro. Revista Brasileira de Fruticultura, Cruz das Almas, v.17, n.2, p.127-129, 1995.

LIMA, A.A. Maracujá produção: aspectos técnicos. Cruz das Almas: Embrapa Mandioca e Fruticultura, Brasília: Embrapa Informação Tecnológica, 2002. 104p.

MORGADO, I.F. Resíduos agroindustriais prensados como substrato para a produção de mudas de Eucalyptus grandis Hill ex Maiden e Saccharum spp. 1998. 102f. Tese (Doutorado em Produção Vegetal) - Universidade Estadual do Norte Fluminense, Campos dos Goytacazes, 1998.

OLIVEIRA, R.P.; SCIVITARO, W.B.; VASCONCELLOS, L.A.B. Avaliação de mudas de maracujazeiro em função do substrato e do tipo de bandeja. Scientia Agricola, Piracicaba, v.50, n.3, p.261266, 1993.

PEIXOTO, J.R; PÁDUA, T. Efeito da matéria orgânica, do superfosfato simples e do cloreto de potássio na formação de mudas do maracujazeiro amarelo. Pesquisa Agropecuária Brasileira, Brasília, v.24, n.4, p.417-422, 1989.

PEIXOTO, J.R.; PAIVAJR., M.C.; ANGELIS, B.; OLIVEIRA, J.A. Adubação orgânica e fosfatada no desenvolvimento de mudas de maracujazeiro amarelo (Passiflora edulis Sims f. flavicarpa Deneger). Revista Brasileira de Fruticultura, Jaboticabal, v.21, n.1, p.49-51, 1999. 
PEREIRA, W.E.; LIMA, S.F.; PAULA, L.B.; ALVAREZ, V.H.V. Crescimento e composição mineral de mudas de maracujazeiro em função de doses de osmocote em dois tipos de substratos. Revista Ceres, Viçosa, v.47, n.271, p.311-324, 2000.

SÃO JOSÉ, A.R.; SOUZA, I.V.B.; LEITE, M.J.N.; DUARTE FILHO, J.; ATAÍDE, E.M.; ANJOS, D.A. Influence of four substracts on growth and vigour of passion fruit (P. edulis Sims f. flavicarpa Deg.) seedlings. In.: INTERNATIONAL SYMPOSIUM ON TROPICAL FRUITS, 1, Vitória-ES, 1993. Anais... SBF/ISHS, 1993. CD Rom.

SAS Institute. SAS user's Guide: statistical analysis system (6.12). Cary, 1998. 846p.

SCHIAVO, J.A.; MARTINS, M.A. Produção de mudas de goiabeira (Psidium guajava L.) inoculadas com o fungo micorrízico arbuscular Glomus clarum em substrato agro-industrial. Revista Brasileira de Fruticultura, Jaboticabal, v.24, n.2, p.519-523, 2002.
SERRANO, L.A.L.; MARINHO, C.S.; CARVALHO, A.J.C.; MONNERAT, P.H. Efeito de sistemas de produção e doses de adubo de liberação lenta no estado nutricional de porta-enxerto cítrico. Revista Brasileira de Fruticultura, Jaboticabal, v.26, n.3, p.524-528, 2004.

SILVA, R.P.; PEIXOTO, J.R.; JUNQUEIRA, N.T.V. Influência de diversos substratos no desenvolvimento de mudas de maracujazeiro azedo (Passiflora edulis Sims f. flavicarpa DEG). Revista Brasileira de Fruticultura, Jaboticabal, v.23, n.2, p.377381,2001 